\title{
BONE MARROW TREPHINE BIOPSY IN HAEMATOLOGICAL DISEASES: A STUDY OF 53 CASES
}

\begin{abstract}
KHATUN $\mathrm{H}^{1}$, AFROSE $\mathrm{S}^{2}$, KHAN MA ${ }^{3}$, ARA T ${ }^{4}$, ISLAM MS ${ }^{5}$, BISWAS AR ${ }^{6}$
Abstract:

Bone marrow aspiration (BMA) and biopsy (BMTB) are important investigations for diagnosis of haematolgical malignancies and non-malignant diseases both in adults and children. BMA and BMTB are complementary and if both are done a comprehensive analysis of bone marrow involvement is possible. 53 cases of BMTB were studied in order to underscore the indications and importance of BMTB. BMTB was done to determine cellularity in aplastic anaemia (AA) $(33.96 \%, n=18)$ and in cases of failure of aspiration $(32.08 \%, n=17)$. Failure of aspiration was attributable to bone marrow (BM) fibrosis $(76 \%, n=13)$ due to acute leukaemia $(35.30 \%, n=6)$ and myelofibrosis $(43.17 \%, n=7)$. BMTB upstaged non Hodgkin's lymphoma (NHL) from IIIB to IVB in $22.22 \%$ cases. 1 case of $A A$ showed focal lymphoid aggregate which later evolved into acute lymphoblastic leukaemia (ALL). BMTB is a safe procedure and increased bleeding was noted only in a case of polycythaemia vera.
\end{abstract}

Key words: Bone marrow aspiration, bone marrow biopsy, aplastic anaemia, haematological malignancy.

J Dhaka Med Coll. 2013; 22(2) : 207-210.

\section{Introduction:}

Obtaining bone marrow, by aspiration and biopsy is critical for diagnosis, prognostic evaluation and response monitoring in Haematological malignancies ${ }^{1,2}$. BMTB is superior to assess cellularity, degree of fibrosis, marrow architecture and focal marrow infiltration in lmphoma. It can also provide sample for immunohistochemistry although not for cytogenetic study. Biopsy is also required when a 'dry tap 'or 'blood tap' commonly associated with acute megakaryoblastic leukemia (AML- FAB-M7), acute panmyelosis with myelofibrosis and primary myelofibrosis $(\mathrm{PMF})^{3,4}$. Abnormal localization of immature precursors (ALIP) in MDS and nodular partial remission (nPR) in chronic lymphocytic leukaemia (CLL) can be assessed only by $\mathrm{BMTB}^{5}$. BM aspirate along with trephine biopsy is required for diagnosis and staging of nonHodgkin's lymphoma (NHL) and Hodgkin's lymphoma (HL) $)^{6,7}$.

\section{Methods:}

This study was done at the Department of Haematology, Dhaka Medical College Hospital, Dhaka from January to June 2013. The diagnosis of lymphoma was confirmed by lymph node biopsy and histopathology prior to staging bone marrow biopsy. Under informed consent, BMTB was done in posterior superior iliac spine under strict aseptic condition and local anaesthesia using Islam needle. Obtained core was preserved in formalin and touch imprints were prepared. Imprints were stained with Leishman stain and core was sent to a collaborating laboratory for histopathology.

1. Dr. Hazera Khatun, Specialist in Haematology, Square Hospital, Dhaka.

2. Dr. Salma Afrose, Associate Professor, Department of Haematology, Dhaka Medical College and Hospital, Dhaka.

3. Dr. Mohiuddin Ahmed Khan, Professor \& Head, Department of Haematology, Dhaka Medical College and Hospital, Dhaka.

4. Dr. Tasneem Ara, Assistant Professor, Department of Haematology, Dhaka Medical College and Hospital, Dhaka.

5. Dr. Mohammad Sirajul Islam, Assistant Professor, Department of Haematology, Sir Salimullah Medical College and Mitford Hospital, Dhaka.

6. Dr. Akhil Ranjan Biswas, Assistant Professor, Department of Haematology, Dhaka Medical College and Hospital, Dhaka. Correspondence : Dr. Hazera Khatun, Specialist in Haematology, Square Hospital, Dhaka. Cell Phone: +8801923745775, Email: drhazerak56@gmail.com 


\section{Results:}

In a period of 6 month, BMTB was performed in 53 cases. Out of theses 18 cases $(34.61 \%)$ was AA. 4 cases each of ALL, lymphoma and PMF followed by acute myeloid leukaemia (AML) $(\mathrm{n}=3,5.76 \%)$, chronic myeloid leukaemia (CML) and secondaries $(\mathrm{n}=2,3.84 \%)$ [fig. 1]. 1 case each of multiple myeloma (MM) and polycythaemia rubra vera (PRV). 5 cases showed reactive changes and 6 cases showed normal active marrow. 2 cases showed erythroid hyperplasia (both done to stage lymphoma) and

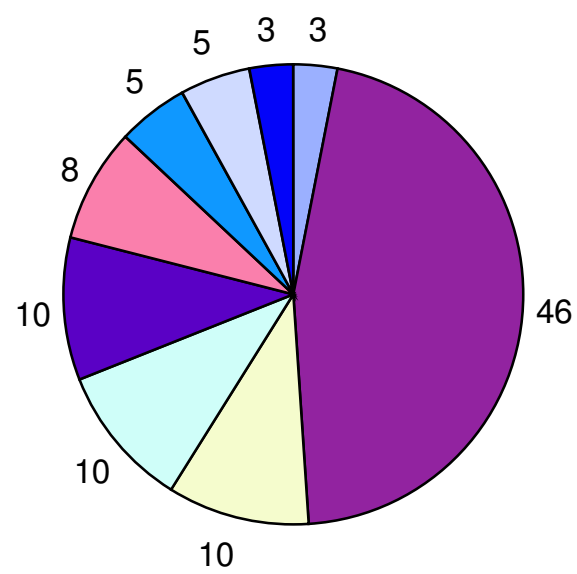

Fig.-1: Findings in bone marrow biopsy

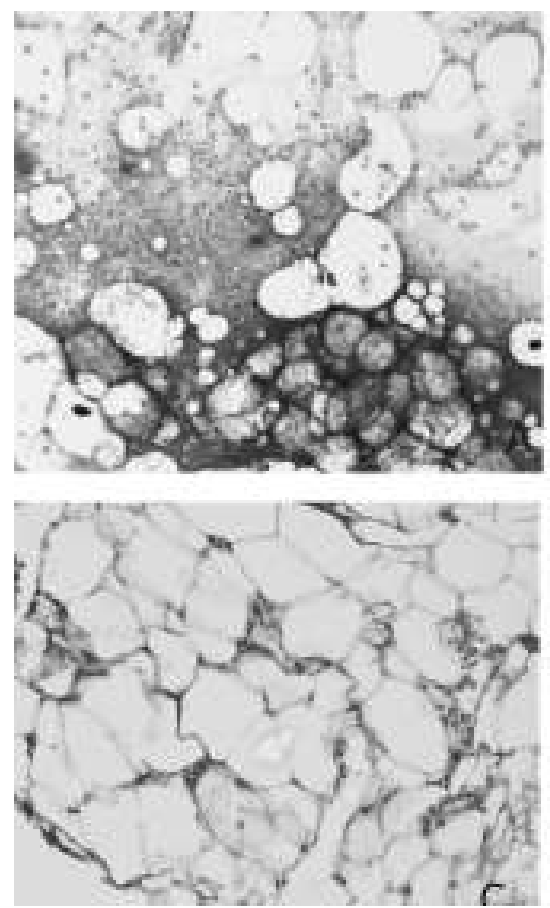

1 case showed megakaryocytic hyperplasia (done to investigate thrombocytopenia). BMTB was done to assess the marrow cellularity in AA $(n=18,33.96 \%)$ which constitute an essential diagnostic criteria. In AA bone marrow was grossly hypocellular with increased fat spaces. Erythropoietic and granulopoietic

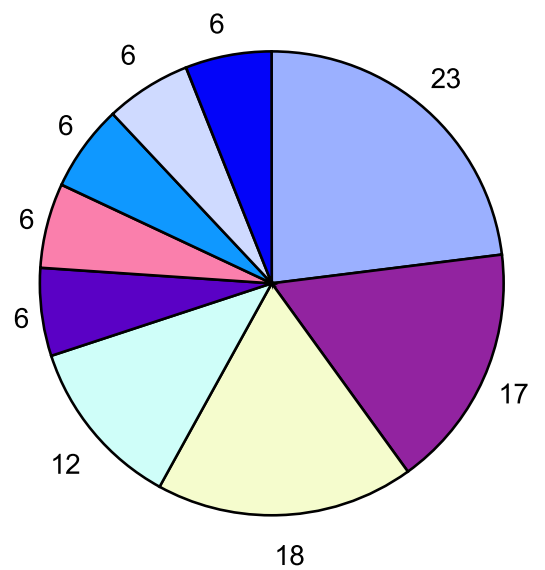

Fig.-2: Biopsy findings in failed aspirations

elements were very scanty and megakaryocytes were virtually absent [fig. 3]. The second commonest indication was failure of bone
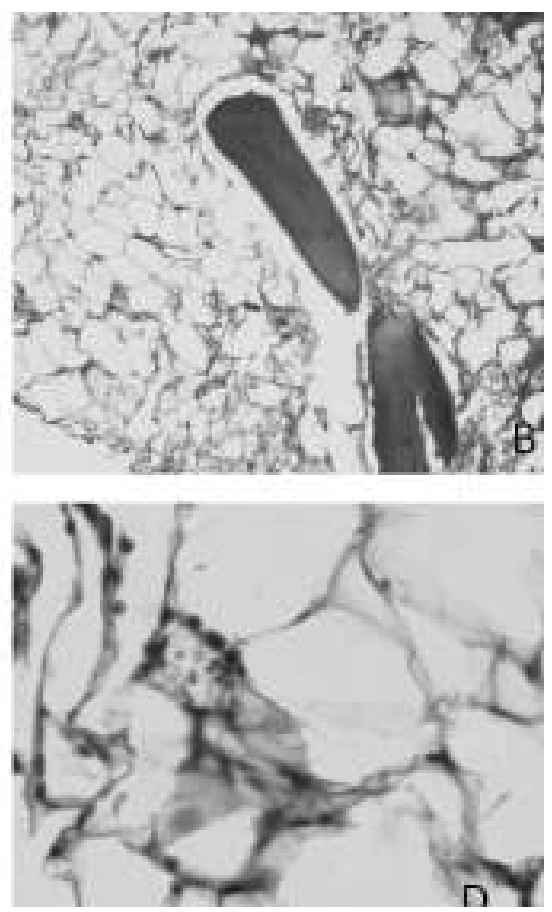

Fig .-3: Aplastic anaemia aspiration and biopsy feature: spirate shows hypocellular marrow with increased fat spaces and one megakaryocyte; $A(\times 10$ objective); $B(\times 10$ objective); $C(\times 40$ objective); $D$ $(\times 100$ objective). Biopsy shows grossly hypocellular marrow with increased fat spaces and no megakaryocytes. [A - Leishman stain; B,C and D-H\&E stain]. 
marrow aspiration $(n=17.32 .08 \%)$ followed by staging of lymphoma ( $n=12,22.64 \%)$. Out of 17 cases of failed aspiration, 65\% was blood tap (yielding only blood in aspiration; $\mathrm{n}=11$ ) and $35 \%$ was dry tap (yielding no blood or marrow particles in aspiration; $n=6)$. Out of the 17 failed aspiration cases, $41 \%(\mathrm{n}=7)$ was due to MPN namely PMF (23\%), PRV (6\%) and CML (12\%). Other causes of failed aspirations were Multiple myeloma (6\%), ALL (17\%), AML (18\%) and secondary deposits in the bone marrow $(6 \%)$ [fig. 2]. Marrow in PMF was grossly hypocellular
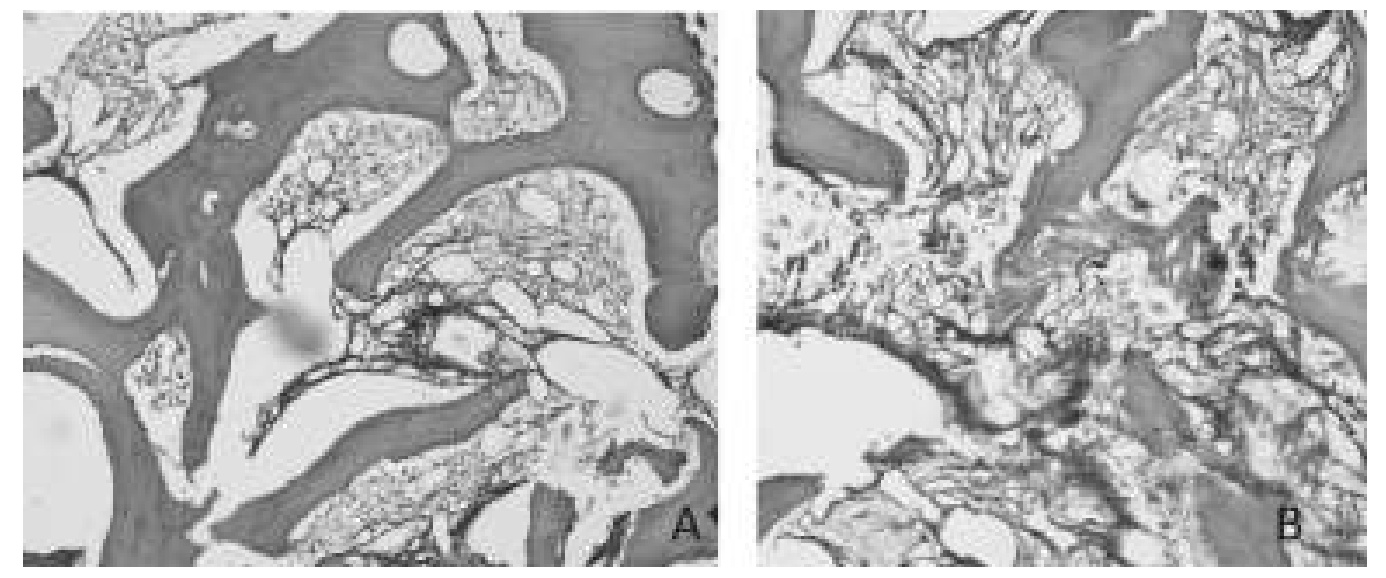

Fig.-4: Fibrotic phase PMF: (A) Massive widening of bony trabeculae and hypocellularity, (B) Streamlining of megakaryocytes. Abnormal megakaryocyte with cloud like nuclei ( $\times 10$ objective) [H \& E stain].

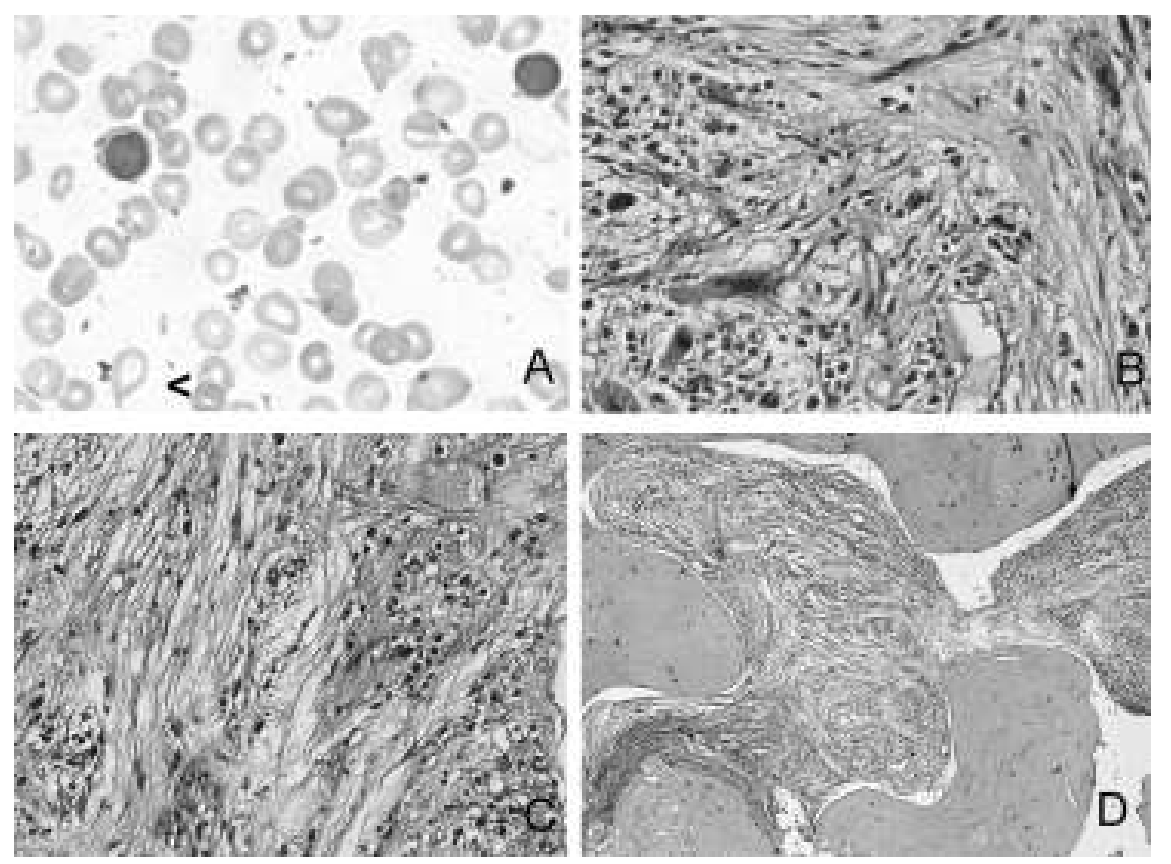

Fig.-5: PMF features in blood and marrow: (A) peripheral blood shows dacryocytes (arrow head marked) and myeloblast (oil immersion objecive); (B) trephine biopsy shows large megakaryocytes with bulbous deeply lobated nuclei. ( $\times 40$ objective); $(C \& D)$ marked reticulin fibrosis in marrow $(\times 40$ and $\times 10$ objective respectively) [ $A$ - Leishman stain; $B-H \& E$ stain; $C$ and $D$ - Silver impregnation stain]. 


\section{Discussion:}

BMTB is a relatively safe procedure with adverse event reported in only .12 to $.34 \%$ of procedures. Major risk factor for haemorrhgae was MPD and we found increased bleeding in a case of polycythaemia vera ${ }^{8}$. Aspiration failure was found attributable to fibrosis in $58.8 \%$ cases $(\mathrm{n}=10)$. Cases included ALL, AML and $\mathrm{PMF}^{8-10}$. PMF comprised $23.5 \%$ of the cases which is similar to another study by Barua et al. ${ }^{10}$ This was higher than found by Humphries ${ }^{9}$ (13.8\%). This is likely due to the small number of patients included in the study. In $35.3 \%$ cases of aspiration failure may be due to acute leukaemia similar to $41.3 \%$ demonstrated by Barua et $\mathrm{al}^{10}$. BMTB is recommended in the diagnostic work up for AA to establish the degree of cellularity and exclude differential diagnoses like hypocellular ALL and hypocellular MDS ${ }^{11}$. 1 patient labeled as severe aplastic anaemia (SAA) out of 18 cases of AA, evolved into ALL 2 months later while she was still on CSA. Biopsy finding in this case showed focal lymphoid aggregate. Islam et al. ${ }^{12}$ found that $10 \%$ of the AA cases evolving to acute leukaemia. The rest of the cases of AA $(n=17)$ biopsy findings were typical of AA [figure 3]. In one case of AA, aspirate showed only mildly depressed megakaryopoiesis but biopsy showed no megakaryocytes underscoring the importance of obtaining a core of bone marrow to avoid false impression of patchy haemopoiesis in AA. Staging of lymphoma specially NHL requires a bone marrow biopsy rather than aspiration as focal infiltrates may be missed by aspiration as such cases can be upstaged after bone marrow biopsy. BMTB was done in 12 cases of lymphoma (3 HL and 9 NHL). In contrast to Subramanium et al. ${ }^{7}$ and Hamid \& Naeem ${ }^{13}$ BMTB failed to upstage HL in our study. 1 case of HL stage IIB BMA showed features of lymphoid infiltration, however, in biopsy no infiltration was found. This was probably aspiration from a normal lymphoid nodule in the bone marrow. 22.22 \% of NHL cases $(n=2)$ BM biopsy showed lymphomatous infiltration which is higher than the study by Brunning \& McKenna ${ }^{14}$ probably due to larger sample size. Both the cases in current study were at clinical stage IIIB upstaged to IVB after biopsy.

\section{Conclusion:}

This was a small study of 53 cases. We strongly believe that extending this study can produce valuable results. The necessity of BMTB in NHL particularly merits further evaluation with higher number of patients. However, in resource-poor setting as ours, performing BMTB in strict indications can limit diagnostic failure in patients.

\section{References:}

1. Bates I. Bone marrow biopsy. In: Lewis S M, Bain BJ, Bates I. eds. Practical haematology. $10^{\text {th }}$ ed. Philadelphia: Elsevier; 2007. p.116-30.

2. Bain BJ, Bailey K. Pitfalls in obtaining and interpreting bone marrow aspirates: to err is human. J Clin Pathol 2011; 64(5): 373-9.

3. Campbell P J, Green A R. Myeloproliferative neoplasms. In: Hoffbrand AV, Catovsky D, Tuddenham EG, Green AR. eds. Postgraduate haematology. $6^{\text {th }}$ ed. Sussex: Willey Blackwell; 2011. p.697-701.

4. Thiele $J$, Piere R, Imbert $M$, et al. eds. Chroinc myeloproliferative disorders. In: Jaffe ES, Harris N L, Stein H, Vardiman JW. eds. Patholgy and genetics of tumours of haematopoietic and lymphoid tissues. Lyon: IARC Press; 2008. p.35-8.

5. Catovsky D, Montserrat E. Chroinc lymphocytic leukaemia and other B- cell disorders. In: Hoffbrand AV, Catovsky D, Tuddenham EG, Green AR. Postgraduate haematology. $6^{\text {th }}$ ed. Sussex: Willey Blackwell; 2011. p. 530-57.

6. Fend F, Kremer M. Diagnosis and classification of malignant lymphoma and related entities in the bone marrow trephine biopsy. Pathobiology 2007; 74(2): 133-43.

7. Subramanian R, Basu D, Badhe B, Dutta TK. Role of bone marrow trephine biopsy in the diagnosis of marrow involvement in Hodgkin's disease. Indian J Pathol Microbiol 2007; 50(3): 640-3.

8. Malempati S, Joshi S, Lai S, Braner DAV, Tegtmeyer K. Bone marrow aspiration and biopsy. N Engl J Med 2009; 361(15): 28.

9. Humphries JE. Dry tap bone marrow aspiration: clinical significance. Am J Hematol 2006; 35(4): 247-50.

10. Barua AR, Rahman J, Tariquzzaman M, Barua D. Histomorphological patterns in 50 bone marrow aspiration failure cases. Bangladesh $\mathrm{J}$ Pathol 2010; 25(1): 18-22.

11. Marsh JC, Ball SE, Cavenagh J, Darbyshire P, Dokal I, Gordon-Smith EC, et al. Guidelines for diagnosis and management of aplastic anaemia. Br J Haematol 2009; 147(1): 43-70.

12. Islam MS, Hossain MZ, Aziz MA, Begum M, Rahman MJ, Ara T. A prospective study on response of immunosuppressive therapy with cyclosporine and prednisolone in acquired aplastic anaemia. J Dhaka Med Coll 2010; 19(2): 80-5.

13. Hamid A, Jabbar N, Naeem S. Significance of bone marrow biopsy in staging of Hodgkin's lymphoma. Ann King Edward Med Univ 2010; 16(1): 12-6.

14. Brunning RD, McKenna R. eds. tumours of bone marrow. In: Atlas of tumour pathology. Washington DC: Armed Forces Institute of Pathology; 1999. 